\title{
Gene-to-trait knowledge graphs show association of plant photoreceptors with physiological and developmental processes that can confer agronomic benefits
}

Hamebantei Mawkhiew

Saint Edmund's College, Meghalaya

Lingaraj Sahoo

IIT Guwahati: Indian Institute of Technology Guwahati

Eros Kharshiing ( $\square$ eros.kharshiing@gmail.com )

St. Edmund's College, Meghalaya https://orcid.org/0000-0002-5570-8669

\section{Short Report}

Keywords: Crop physiology, Gene discovery, Knowledge graphs, Molecular breeding, Photoreceptors, Plant development

Posted Date: February 23rd, 2021

DOl: https://doi.org/10.21203/rs.3.rs-247752/v1

License: (c) (1) This work is licensed under a Creative Commons Attribution 4.0 International License.

Read Full License 


\section{Abstract}

Global population growth, climate change, altered precipitation rates and cropping patterns are increasingly challenging plant scientists to improve crop productivity for food and non-food applications. Hence, there is a pressing need for identifying candidate gene that can be targeted for breeding future crops having enhanced agronomic benefits. Network mapping utilises available data and creates knowledge graphs that aid in visualising association(s) between the individual data items. Here, we have generated gene-to-trait knowledge graphs of known plant photoreceptors using the KnetMiner gene discovery platform which generates biological networks from literature/data sets available in public databases. The resulting knowledge graphs indicate a close association of photoreceptors with various physiological and developmental processes such as shoot architecture, yield, disease resistance and water use efficiency among others, that can confer agronomically important benefits. Such information can be of assistance to plant biologists in the selection of potential gene targets for improving agronomically beneficial traits in plants. This report highlights the potential of machine learning and knowledge graphs as aids in more efficient knowledge discovery and novel decision-making processes which can also be employed for crop breeding or crop engineering.

\section{Full Text}

Due to technical limitations, full-text HTML conversion of this manuscript could not be completed. However, the manuscript can be downloaded and accessed as a PDF.

\section{Figures}



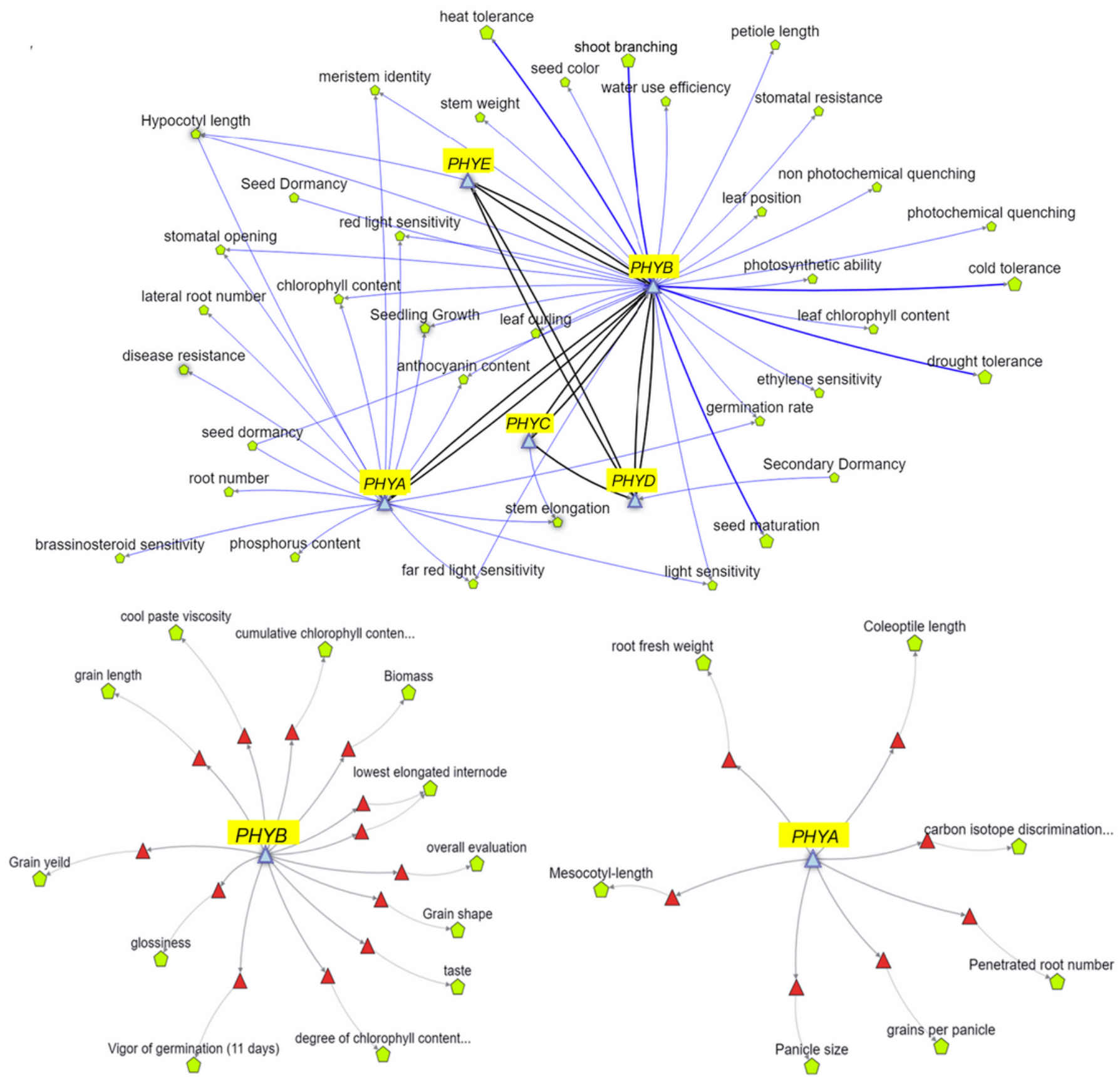

\section{Figure 1}

Network associations of phytochrome red/far-red light photoreceptor (PHY) genes in Arabidopsis (top) and rice (bottom) with various physiological and developmental processes (green pentagons) that can influence agronomic traits in plants. Red triangles indicate quantitative trait loci. The interactions among the different PHYs in influencing these processes are also shown (black arrows). Network maps for visualising gene-to-trait relationships were generated using KnetMiner (https://knetminer.com) following the instructions available. 

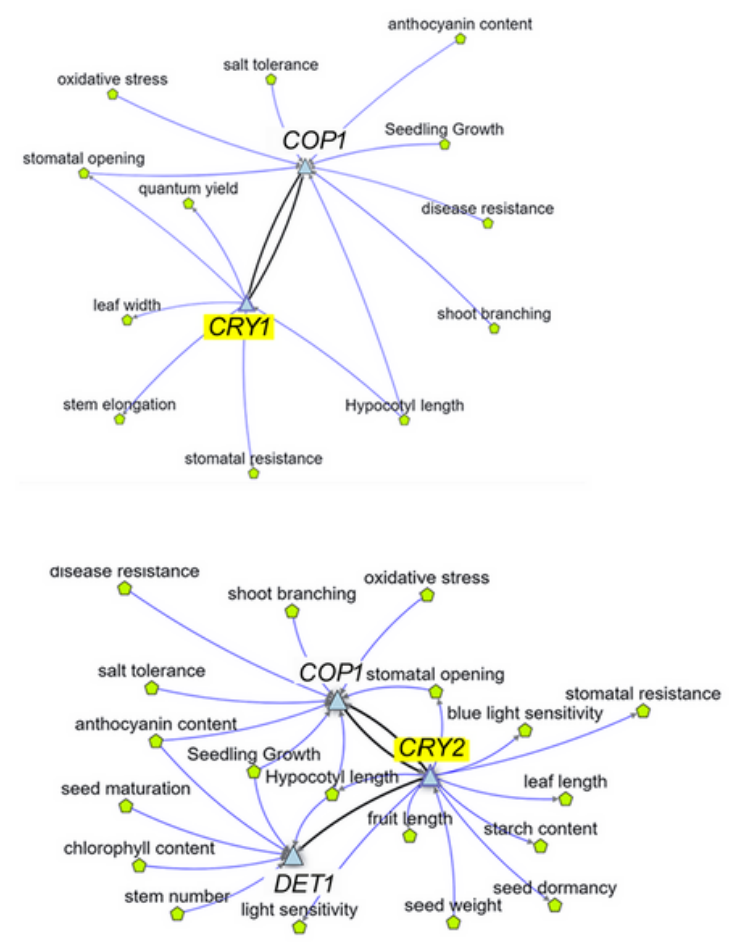
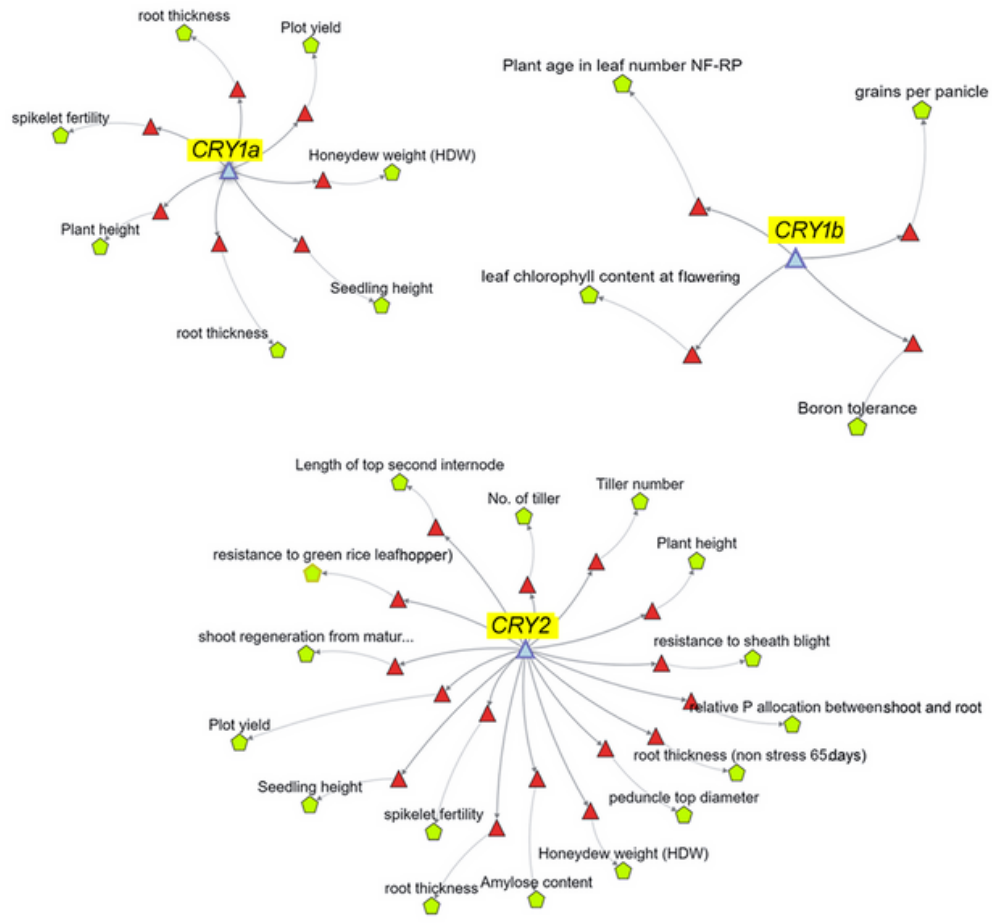

\section{Figure 2}

Network associations (blue arrows) of cryptochrome UV-A/blue-light photoreceptor (CRY1 and CRY2) genes in Arabidopsis (left) and rice (right) with various physiological and developmental processes (green pentagons) that can influence agronomic traits in plants. Red triangles indicate quantitative trait loci. The interactions among the different CRYs in influencing these processes are also shown (black arrows). Network maps for visualising gene-to-trait relationships were generated using KnetMiner (https://knetminer.com) following the instructions available. 

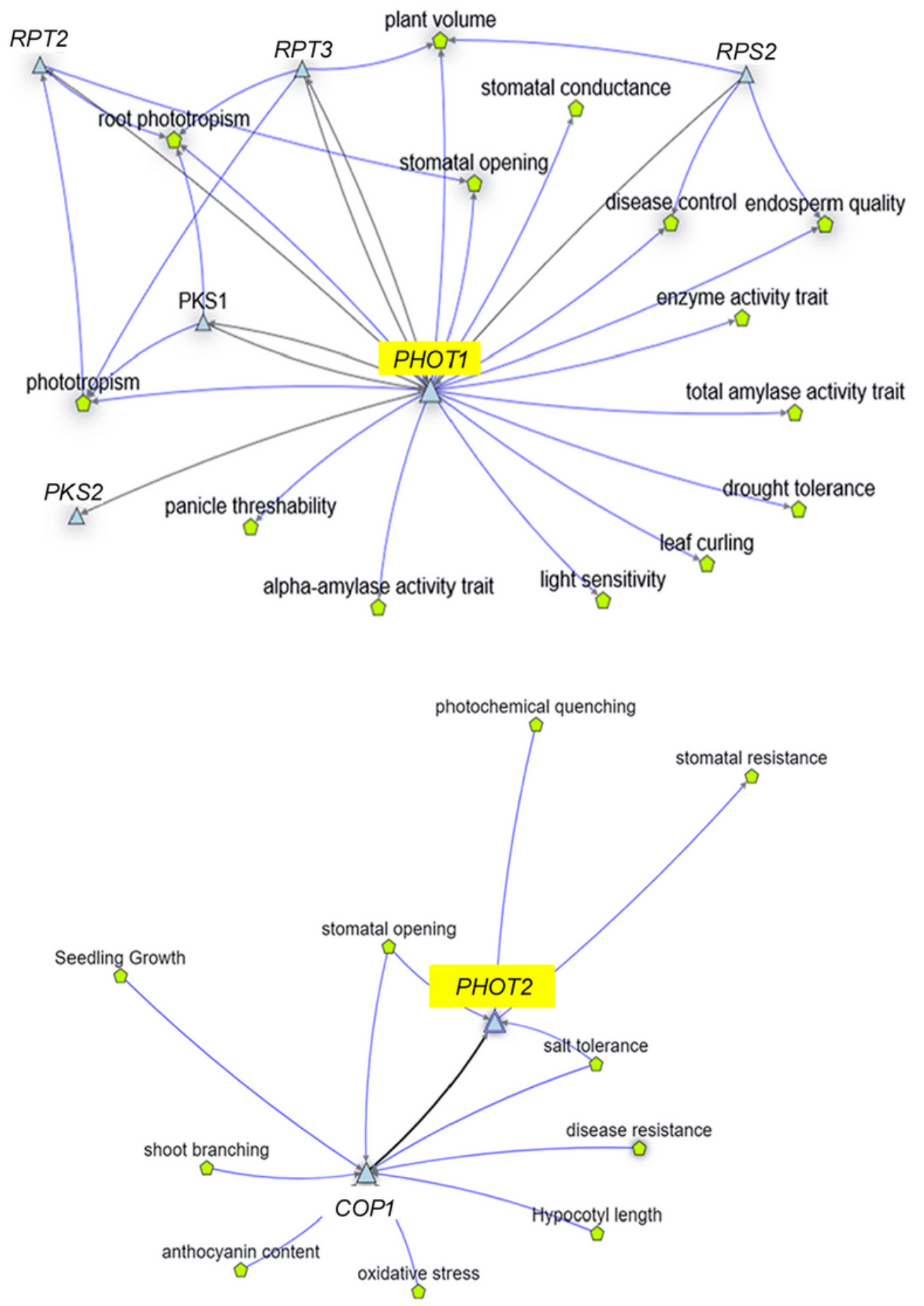

\section{Figure 3}

Association of phototropin (PHOT1 and PHOT2) with plant processes that can confer agronomic benefits in crops. The associated physiological and developmental processes are shown in green pentagons and the interactions of PHOT1 and PHOT2 with other genes in regulating these processes are shown with black arrows. Network maps for visualising gene-to-trait relationship were generated using KnetMiner (https://knetminer.com) following the instructions available. 


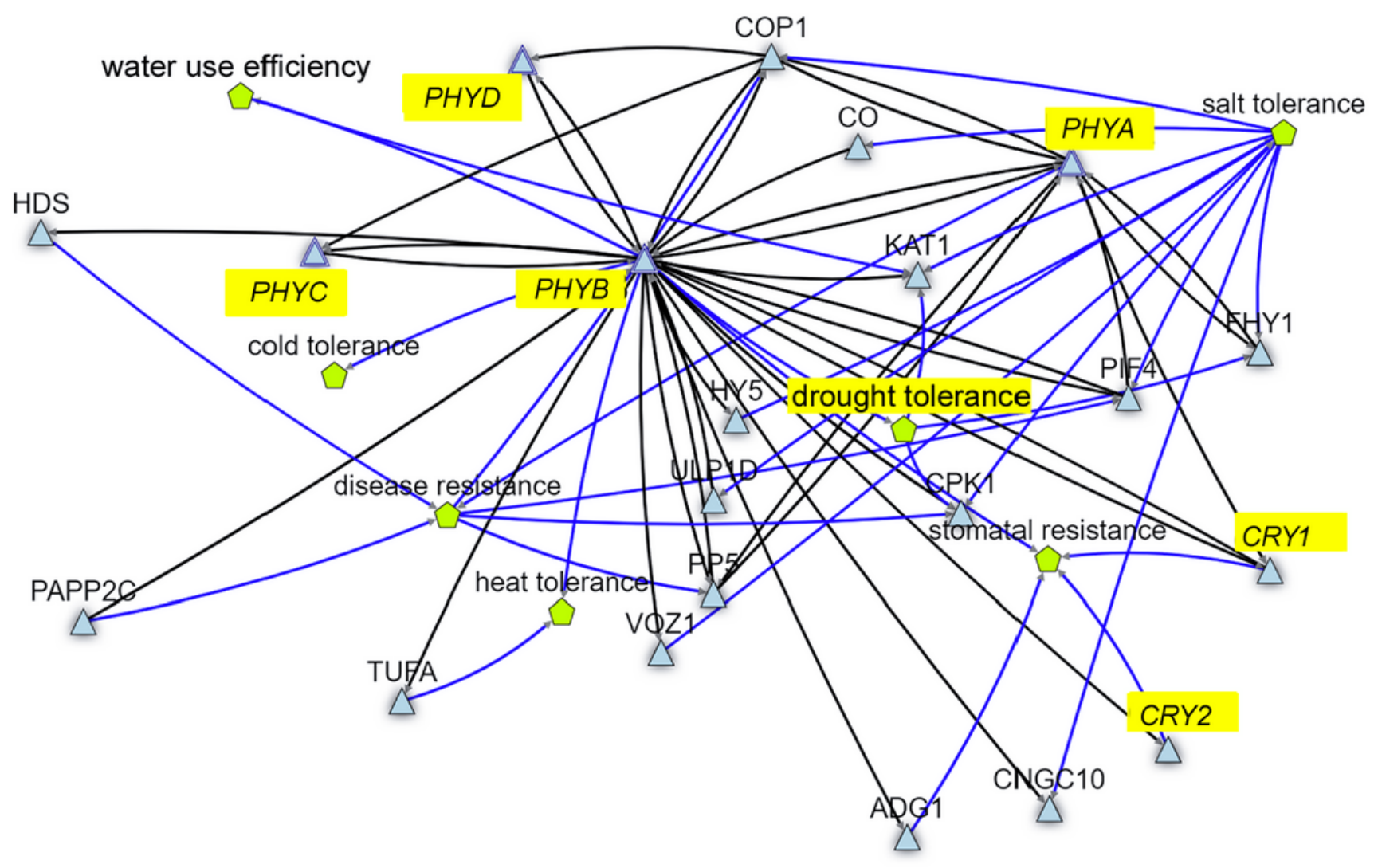

Figure 4

Knowledge graphs showing association of different plant photoreceptors with plants process that can enhance water use efficiency in crop plants. The associated plant processes are shown in green pentagons and the interactions among the different genes in regulating these processes are shown with black arrows. Network maps for visualising gene-to-trait relationships were generated using KnetMiner (https://knetminer.com) following the instructions available. 